\title{
Primeiro registro de Chalcodermus bicolor (Coleoptera: Curculionidae) em plantios de eucalipto
}

\author{
First record of Chalcodermus bicolor in eucalypt plantations
}

\author{
Rodolfo Molinário de Souza ${ }^{\mathrm{I} *}$ Norivaldo dos Anjos ${ }^{\mathrm{I}}$ Reginaldo Gonçalves Mafia ${ }^{\mathrm{II}}$ \\ João Bosco da Silva ${ }^{I I}$
}

\section{- NOTA -}

\section{RESUMO}

Este trabalho objetivou relatar, pela primeira vez o ataque de um besouro podador em plantios de clones híbridos de eucalipto (Eucalyptus urophylla vs. E. grandis), localizados nos Estados da Bahia e do Espírito Santo. A espécie foi determinada como sendo Chalcodermus bicolor Fiedler, 1936 (Curculionidae: Molytinae). A fêmea poda os ponteiros e constrói um pequeno orifício onde deposita um único ovo, logo abaixo do ponto de incisão. O eucalipto é o primeiro hospedeiro relatado para esta espécie de besouro.

Palavras-chave: entomologia florestal, Curculionidae, Eucalyptus.

\section{ABSTRACT \\ This research aimed to record, for the first time, the damage caused by a pruner beetle on hybrid eucalypts cloned trees (Eucalyptus urophylla vs. E. grandis), located in Bahia and Espírito Santo States, Brazil. The specie was determined as Chalcodermus bicolor Fiedler, 1936 (Curculionidae: Molytinae). The female prunes the tree shoot and lays a single egg inside a small hole, just below the incision point. Eucalypt is the first host recorded to this pruner beetle specie.}

Key words: forest entomology, Curculionidae, Eucalyptus.

Em várias regiões do país onde o eucalipto é plantado são frequentes os problemas enfrentados pelos produtores florestais com os besouros desfolhadores, com destaque para aqueles da família Chrysomelidae, como por exemplo, Costalimaita ferruginea (Fabricius), que atualmente é considerado o mais importante besouro desfolhador de eucalipto do Brasil (ANJOS \& MAJER, 2003). Não menos importantes são os besouros da família Curculionidae, destacando-se a espécie exótica Gonipterus scutellatus Gyllenhal (WILCKEN et al., 2008) e as espécies do gênero Naupactus Dejean que constitui o grupo com maior quantidade de espécies nativas registradas na cultura do eucalipto (SILVA et al., 1968).

Em março de 2008, em plantios comerciais de eucalipto localizados nos municípios de Alcobaça (17 $28^{\prime} 57^{\prime}$ ' S, 39 $16^{\circ} 17^{\prime \prime}$ W e $22 \mathrm{~m}$ de altitude) e Caravelas (17 $43^{\prime} 55^{\prime \prime} \mathrm{S}, 3^{\circ} 15^{\prime} 57^{\prime \prime} \mathrm{W}$ e $10 \mathrm{~m}$ de altitude), no Estado da Bahia, e em junho do mesmo ano no município de Aracruz (1949'13' S, 40¹6'24"' W e 60m de altitude), no Espírito Santo, foram observadas árvores clones de híbridos de Eucalyptus urophylla vs. E. grandis, plantadas em espaçamento $3 \mathrm{~m}$ x $3 \mathrm{~m}$, danificadas nos ponteiros por um inseto desconhecido da família Curculionidae. Nos municípios de Alcobaça e Caravelas, ponteiros danificados foram observados em


respectivamente, e com idades variando de 2 a 3 meses em Alcobaça e de cinco meses em Caravelas. Já em Aracruz os danos foram observados em dois talhões

'Departamento de Biologia Animal, Laboratório de Manejo de Pragas Florestais, Universidade Federal de Viçosa (UFV), 36570 000, Viçosa, MG, Brasil. E-mail: molinariodesouza@gmail.com. *Autor para correspondência.




com área igual a 56,2 e 103,3ha e idade de quatro e três meses, respectivamente. Em 100 árvores avaliadas em cada talhão o percentual médio de ataque foi $38,3 \pm 10,1 \%$, $16,8 \pm 2,6 \%$ e $15,0 \pm 5,0 \%$ para Caravelas, Alcobaça e Aracruz, respectivamente. Portanto, este trabalho tem por objetivo identificar, documentar a ocorrência e descrever alguns aspectos da biologia e dos danos causados às árvores por esse inseto.

Nos locais onde foram observados os danos, vistorias foram realizadas em diferentes horários (alvorecer, meio do dia e crepúsculo) para coleta de indivíduos e observações diretas de sua biologia. Para comprovar a associação do inseto com os danos observados no campo, adultos coletados foram levados para o laboratório, onde foram armazenados em potes plásticos transparentes $(20 \times 15 \mathrm{~cm})$ e fechados com tecido do tipo organza. Como substrato, foram oferecidos ramos de eucalipto intactos do mesmo material genético atacado no campo. Os insetos foram observados a cada 12 horas durante um período de 48 horas. Posteriormente, observações diagnósticas da morfologia externa de ovos, larvas e adultos foram realizadas com auxílio de um microscópio estereoscópico (aumento de 5 a 20X). Exemplares adultos foram enviados ao Dr. Germano H. Rosado Neto, do Departamento de Zoologia da Universidade Federal do Paraná, para identificação.

As larvas de último instar coletadas no campo foram colocadas em recipientes de vidro $(17 \mathrm{~cm}$ de altura x $5,5 \mathrm{~cm}$ de diâmetro), contendo uma camada de cinco centímetros de solo do tipo latossolo vermelho-amarelo. Estes recipientes foram mantidos em condições controladas de temperatura $\left(26 \pm 1^{\circ} \mathrm{C}\right)$, umidade relativa do ar $(60 \pm 2 \%)$ e fotofase de 12 horas, até a emergência da imago.

O besouro responsável pelos ataques às árvores híbridas de $\boldsymbol{E}$. urophylla vs. $\boldsymbol{E}$. grandis foi identificado como Chalcodermus bicolor Fiedler, 1936 (Col.: Curculionidae: Molytinae) e os exemplares foram depositados na Coleção Entomológica Padre Jesus S. Moure do Departamento de Zoologia da Universidade Federal do Paraná (DZUP). As injúrias causadas às árvores por $\boldsymbol{C}$. bicolor em laboratório foram as mesmas observadas no campo, ou seja, o adulto poda a haste dos ponteiros através de um corte reto, decepando-o completamente, mas em alguns casos a parte apical se encontrava tombada (Figura 1A). Verificou-se que tanto os ponteiros laterais quanto o principal podem ser podados e, em uma mesma árvore, vários ponteiros foram danificados. Várias outras espécies do gênero Chalcodermus apresentam comportamento daninho semelhante, sendo as injúrias atribuídas às fêmeas que podam suas plantas hospedeiras para ovipositarem
(BONDAR, 1927, 1934, 1939, 1948; PYENSON, 1939). De fato, observou-se que logo abaixo do corte, na parte remanescente do ponteiro podado por C. bicolor, havia um orifício de postura com apenas um ovo e, às vezes, uma larva curculioniforme se desenvolvendo nos tecidos remanescentes do ponteiro. $\mathrm{O}$ fato das fêmeas de $\boldsymbol{C}$. bicolor ovipositarem na parte remanescente do ponteiro difere do observado em outras espécies do gênero. Para as espécies de Chalcodermus relatadas por BONDAR $(1927,1934,1948)$ e PYENSON (1939) a oviposição foi observada na parte removida da planta. Esse padrão ocorre, possivelmente, porque as larvas dessas outras espécies necessitam de tecido vegetal em fermentação para o completo desenvolvimento (BONDAR, 1927, 1934).

Várias espécies do gênero Chalcodermus já foram registradas associadas a outros hospedeiros, nos Estados da Bahia e do Espírito Santo (BONDAR, 1927, 1934, 1939, 1941, 1948, 1949; SAUER, 1941; SILVA et al., 1968). Entretanto, em relação ao eucalipto, uma espécie não identificada de Chalcodermus já foi registrada por BERTI-FILHO (1981) causando danos, semelhantes aos observados para $\boldsymbol{C}$. bicolor, em árvores novas de E. robusta, E. saligna e E. urophylla no Estado do Espírito Santo, sendo este o primeiro relato do gênero associado ao eucalipto. Mas, como o autor não menciona em que museu ou coleção os espécimes foram depositados não é possível afirmar que se trate da mesma espécie apenas com base no que foi relatado. Portanto, esse trabalho registra, pela primeira vez, o eucalipto como primeiro hospedeiro de C. bicolor. Além disso, essa espécie está sendo registrada pela primeira vez nos Estados da Bahia e do Espírito Santo, ampliando sua área de ocorrência natural, que havia sido descrita por FIELDER (1936) apenas para os Estados de Minas Gerais e Goiás. Como muitas das espécies do gênero Chalcodermus podam os brotos de suas plantas hospedeiras, independente do local de oviposição, o termo podador tem sido frequentemente utilizado, como por exemplo, o Podador-do-algodoeiro para $C$. bondari Marshall (BONDAR, 1927) e o Podador-do-cacau para $\boldsymbol{C}$. marshalli Bondar (BONDAR, 1934). Assim, propõe-se para $\boldsymbol{C}$. bicolor a denominação popular de "Podadordo-eucalipto".

Em relação à biologia de $\boldsymbol{C}$. bicolor os conhecimentos se restringem, basicamente, ao trabalho publicado por FIEDLER (1936). Entretanto, pode-se acrescentar que os ovos são de formato elipsoide, esbranquiçados e lisos (Figura 1B). As larvas de último instar são ápodas e recurvadas, com cabeça diferenciada e quitinizada, com abdome de coloração amarelo-clara e, geralmente, noduloso (Figura 1C). A 


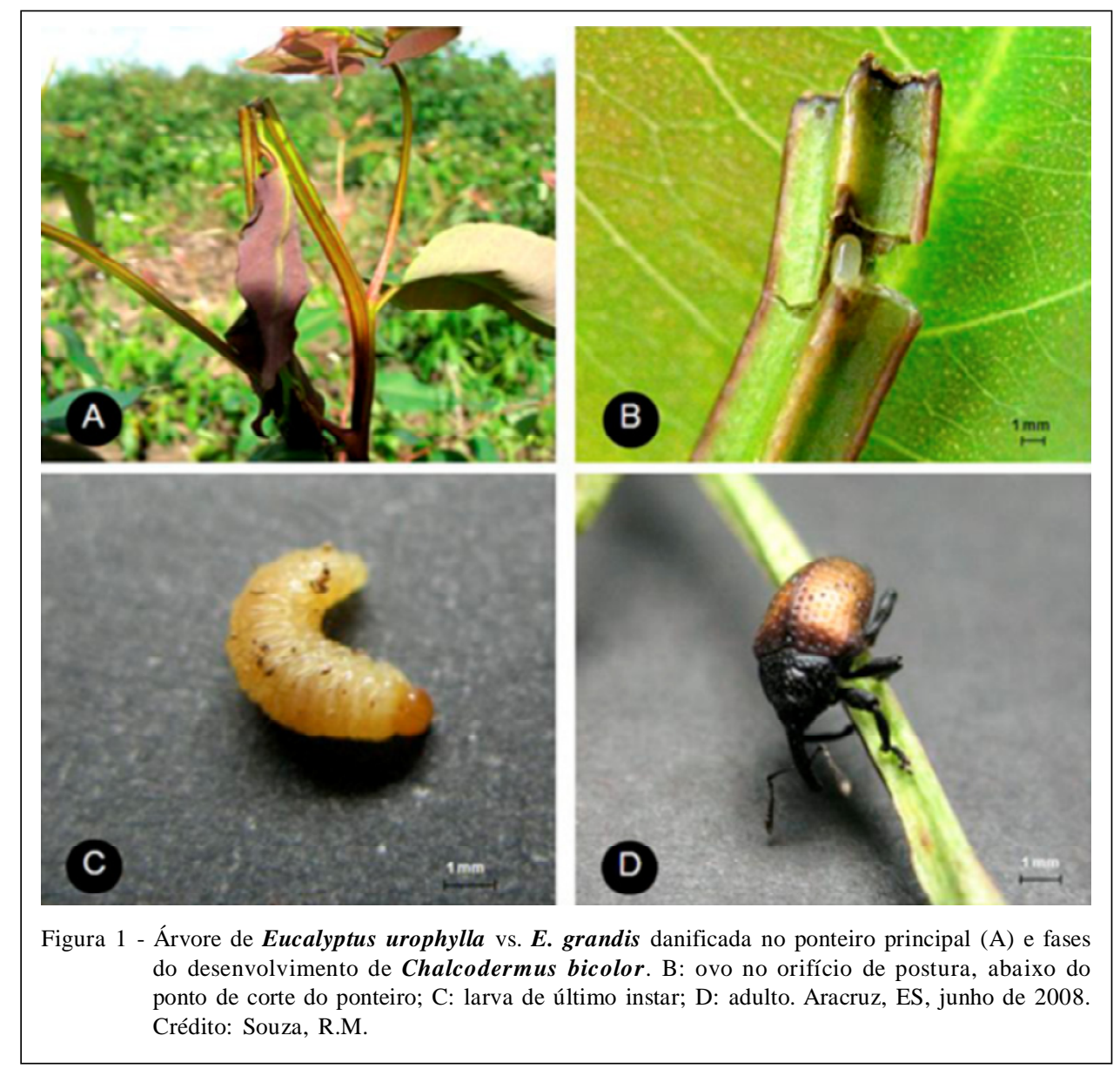

cabeça apresenta coloração mais alaranjada do que o abdome e com uma sutura epicranial bem acentuada. Ao se alimentar, a larva constrói uma galeria longitudinal no sentido do ápice para a base da haste remanescente, sendo que, à medida que ocorre a alimentação, os excrementos são depositados nesta galeria. Quando completamente desenvolvida, a larva faz uma pequena perfuração de saída e se joga no solo para empupar, comportamento similar a outras espécies do gênero (PYENSON, 1939). Das larvas depositadas no recipiente de vidro com solo, os adultos emergiram cerca de 30 dias após o acondicionamento. Os adultos de $\boldsymbol{C}$. bicolor foram de difícil localização no campo, mas podiam ser encontrados fortemente agarrados nas hastes finas dos ramos ou escondidos entre as folhas secas de ponteiros podados ou presentes no solo. Em laboratório, os adultos apresentavam maior atividade durante a noite, permanecendo praticamente imóveis durante o dia. Morfologicamente são de tamanho pequeno, bicolores e sem brilho metálico; corpo preto e élitros castanho-avermelhados, com algumas pontuações pretas, corroborando com FIEDLER (1936) (Figura 1D).

Em casos de surtos populacionais do podador-do-eucalipto, a poda do ponteiro principal pode afetar o crescimento, a produção e proporcionar a formação de árvores de má qualidade. Entretanto, os prejuízos podem se agravar caso a galeria construída pelas larvas seja colonizada por outros organismos. Como os ataques ocorreram em árvores com idade de até cinco meses pós-plantio e por se ter registrado um percentual médio de árvores atacadas de até $38 \%$, acredita-se que $\boldsymbol{C}$. bicolor possa representar um problema para a eucaliptocultura nas regiões onde a espécie foi registrada, sobretudo em condições de manejo inadequado.

\section{AGRADECIMENTOS}

À Coordenação de Aperfeiçoamento de Pessoal de Nível Superior (CAPES) pela bolsa concedida ao primeiro autor e ao Dr. Germano Rosado Neto pela identificação dos exemplares de $\boldsymbol{C}$. bicolor. 


\section{REFERÊNCIAS}

ANJOS, N.; MAJER, J. D. Leaf-eating Beetles in Brazilian eucalypt plantations. Curtin: School of Environmental Biology, 2003. 33p. (Bulletin 23).

BERTI-FILHO, E. Insetos associados a plantações de espécies do gênero Eucalyptus nos Estados da Bahia, Espírito Santo, Mato Grosso do sul, Minas Gerais e São Paulo. 1981. 177f. Tese (Livre Docência) - Departamento de Entomologia, Escola Superior de Agricultura "Luiz de Queiroz", Universidade de São Paulo, SP.

BONDAR, G. Notas entomológicas da Bahia, IV. Revista de Entomologia, v.10, p.1-14, 1939.

BONDAR, G. Notas entomológicas da Bahia, VIII. Revista de Entomologia, v.12, p.427-470, 1941.

BONDAR, G. Notas entomológicas da Bahia, XX. Revista de Entomologia, v.19, p.1-54, 1948.

BONDAR, G. Notas entomológicas da Bahia, XXI. Revista de Entomologia, v.20, p.173-228, 1949.

BONDAR, G. O podador do cacau. Bahia Rural, v.1, p.247248,1934
BONDAR, G. O podador, Chalcodernus bondari, Marsh. Nova praga do algodoeiro na Bahia. Chácaras e Quintais, v.36, p.177-179, 1927.

FIEDLER, C. Bestimmungstabelle der südamerikanischen Arten der Gattung Chalcodermus Schönh. (Coleoptera: Curculionidae: Cryptorhynchinae.). Arbeiten über Morphologische und Taxonomische Entomologie aus Berlin-Dahlem, v.3, p.280-292, 1936.

PYENSON, L. Notes on the biology of the cotton pruner Chalcodermus bondari Marshall. Journal of Economic Entomology, v.32, p.80-83, 1939.

SAUER, H.F.G. Importância, distribuição e inimigos naturais do podador do algodoeiro Chalcodermus bondari Marshall (Col. Curc.). Revista de Entomologia, v.12, p.42-45, 1941.

SILVA, A.G.A. et al. Quarto catálogo dos insetos que vivem nas plantas no Brasil, seus parasitos e predadores. Rio de Janeiro: Ministério da Agricultura, 1968. 622p.

WILCKEN, C.F. et al. Ocorrência de Gonipterus scutellatus Gyllenhal (Coleoptera: Curculionidae) em plantações de eucalipto no Estado do Espírito Santo. Arquivos do Instituto Biológico, v.75, p.113-115, 2008. 